\title{
Reisen mit meiner Patientin
}

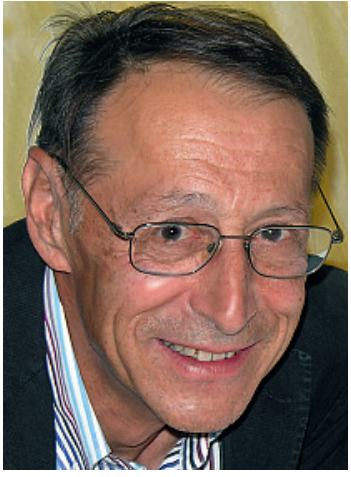

Gerhard Jenzer

Dr. med. Gerhard Jenzer, Fraubrunnen, ist Facharzt für Neurologie FMH und zusammen mit seiner Patientin Sonja Balmer Autor des hier vorgestellten Buches. Sie erreichen ihn unter gejenzer@bluewin.ch.

1 Jenzer G, Balmer S. In der Überlebensfalle. Basel: Schwabe; 2008. www.schwabe.ch.
Die erste Auseinandersetzung mit der amyotrophischen Lateralsklerose (ALS) in der Neurologievorlesung war furchteinflössend. Damals vermittelte uns ein wegen seiner Bulbärparalyse kaum noch sprechfähiger Patient die für den eigenen Leib schier unerträgliche Vorstellung vom hoffnungslos schleichenden Untergang der Muskulatur. Ihre verängstigenden Gesichter zeigte mir die ALS später hin und wieder bei meiner neurologischen Konsiliartätigkeit. So begegnete ich der jungen und lebensfrohen Patientin Sonja Balmer, die schon länger an unklarer Muskelschwäche gelitten hatte. Beim ersten Mal sah ich sie noch am Spitalbettrand, später im Rollstuhl, dann liegend und zuletzt unter Dauerbeatmung. Jahre der ärztlichen Beobachtung und des gegenseitigen Kennenlernens waren verstrichen; der Verlauf der Krankheit hatte uns dazu mehr Zeit eingeräumt als erwartet. Immer wieder verblüffte mich die ohnegleichen bejahende Weise, wie sich diese Patientin mit ihrem Schicksal auseinandersetzte. Sie blieb so aktiv wie nur möglich, äusserte sich zu ihrem Leiden in zahlreichen Medienauftritten, schrieb über ihre Erfahrungen und, so lange die Motorik ausreichte, malte sie Bilder.

Als die Ateminsuffizienz bedrohlich wurde, stand Sonja Balmer vor dem Entscheid über Verzicht auf Leben oder Leben in ultimativer Abhängigkeit: ärztlich, medizintechnisch, pflegerisch, ökonomisch, psychologisch, «palliativ» ... Die letzte Strecke bis zum festen Entschluss war geprägt durch das zunehmende Leiden und die damit anwachsende Bürde der unausweichlichen Richtungsbestimmung. Wo war der Wegweiser, woran sollte sie sich halten? Sie entschloss sich zur Tracheotomie und hängt nun seither sowie auf unbestimmt an dem aus modernster Medizin gesponnenen seidenen Faden. Nachdem die Würfel gefallen waren, sah alles doch anders aus als vorgedacht. Heute lebt, überlebt die Patientin als Gefangene, nicht nur physisch in ihren Apparaten, sondern auch im fortwährenden Zweifel über die Richtigkeit ihres Entschlusses. Das unter derartigen Umständen erreichbare Mass an Lebensqualität, die Besorgnis um den Verlust der Würde, die unaufhörliche Angst vor dem Sterben - mehr als vor dem Tod selbst - sind dabei fortgesetzt belastenden Schwankungen unterworfen.

Das Durchwandern dieses Szenarios in einer etwas entlegenen und wenig zugänglichen Ge- gend schien uns für die Verfassung eines Reiseberichts geradezu verpflichtend. So spannten wir zusammen, als Arzt und Patientin, Kartograph und

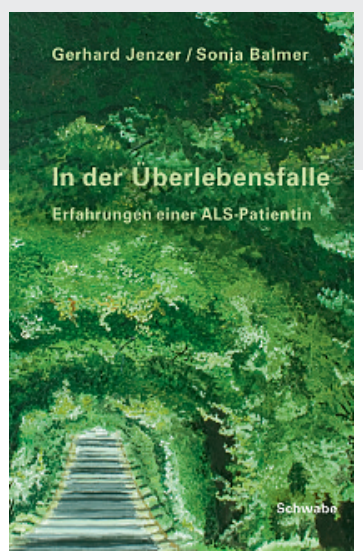

Kundschafterin. Die Bereitschaft und vielmehr sogar der von Sonja Balmer gespürte Auftrag, als authentische Zeugin aufzutreten und ihren Weg unter all diesen Umständen nicht nur Betroffenen, sondern auch einer breiten Öffentlichkeit aufzuzeigen, schienen uns das Wagnis und die Mühen wert, das Projekt anzupacken.

Im Buch «In der Überlebensfalle» [1] wird allgemein verständlich, für eine breite Leserschaft die medizinische Ausgangslage skizziert. Hauptbestandteil sind jedoch die thematisch aus zahlreichen Gesprächen zusammengefassten - wegen der Stimmlosigkeit nur mit einiger Mühe aufgenommenen - Aussagen der mit fast allen Vorkommnissen und Leiden dieses besonderen Schicksals zutiefst vertrauten ALS-Patientin. Sie betrachtet es als wichtige und notwendige Aufgabe, ihr freimütig geschildertes, höchst eigenes Erleben der gewohntermassen dominanten «Objektivität» - aus der medizinischen, pflegerischen und sozialen Perspektive - zur Seite zu stellen.

Von Anbeginn stand für uns fest, über die Option einer Dauerbeatmung bei ALS oder einer vergleichbaren Lähmungssituation lediglich Gelegenheit zu Betrachtung zu geben, Anschauung zu vermitteln, nicht einmal ansatzweise jedoch um Empfehlungen zu ringen, oder uns gar zu einem Verdikt zu versteigen. Gerade dies zu vermeiden, ergibt sich aus der zumindest vorläufigen Erkenntnis eines Zwiespalts, welcher selbst nach gründlichster Abwägung doch allemal einzig durch die Betroffenen selbst zu überwinden ist.

Der Physiker Stephen Hawking hat die künstliche Dauerbeatmung gewollt, die Fernsehmoderatorin Ulla-Carin Lindquist oder der Maler Jörg Immendorf haben sie verworfen. In der notwendigen Diskussion um die Langzeitpflege bei ALS gelten sie als international bekannte Leitfiguren. Sonja Balmer spricht aus ihrer zwar bescheideneren, deswegen jedoch nicht unbeachtlichen Welt.

Gerhard Jenzer 